\title{
Depression in Multiple Sclerosis: A Review of Assessment and Treatment Approaches in Adult and Pediatric Populations
}

\author{
Maria Skokou, Evanthia Soubasi, and Philippos Gourzis \\ Department of Psychiatry, School of Medicine and University Hospital of Patras, University of Patras, \\ Rio, 26504 Patras, Greece \\ Correspondence should be addressed to Philippos Gourzis, pgourzis@upatras.gr
}

Received 26 August 2012; Accepted 17 September 2012

Academic Editors: M. G. Grasso and Y. Wang

Copyright ( 2012 Maria Skokou et al. This is an open access article distributed under the Creative Commons Attribution License, which permits unrestricted use, distribution, and reproduction in any medium, provided the original work is properly cited.

Multiple sclerosis is a chronic demyelinating disease affecting one million people worldwide, with a significant burden of psychiatric comorbidity. Depression is the commonest psychiatric manifestation but still remains largely underdiagnosed and undertreated. The present work reviews current knowledge on diagnosis, assessment, and somatic and psychotherapeutic treatment interventions for depression in adult and pediatric populations of patients with multiple sclerosis.

\section{Introduction}

Multiple sclerosis is a chronic demyelinating disease of the central nervous system, affecting any part of the CNS, but mostly white matter tracts in the cerebral hemispheres, optic nerves, brainstem, cerebellum, and spinal cord [1]. The prevalence of the disorder ranges between 2 and 150/100,000 depending on the country or specific population [2], affecting approximately 1 million people worldwide [3]. Pediatriconset cases comprise $2-5 \%$ of total multiple sclerosis patients [4].

Psychiatric symptoms in the context of MS were first noted by Charcot, who described mania, hallucinations, and depression among other manifestations of the disease [5]. Lifetime prevalence of major depression ranges from 19 to $54 \%$, depending on the population sample and diagnostic criteria used [6-8]. Annual prevalence is estimated at 16\% [9], and point prevalence of clinically significant depressive symptoms is as high as $50 \%$ [10]. The rate of depressive disorders in a pediatric population with demyelinating disease has been estimated at 27\% [11]. Evidently, prevalence is considerably higher than in the general population or among patients with general medical conditions other than MS [8]. Etiologic factors seem to be both biological and psychosocial [12], and risk factors have been reported to be female sex, age $<35$ years, family history of major depression, and a high level of stress [13]. Disease-modifying agents, interferon beta in particular, have also been suspected to induce depressive symptomatology $[14,15]$. However, subsequent well-designed studies failed to prove a depressogenic effect, and pretreatment depressed mood was found to be the best predictor of subsequent depression $[16,17]$. The importance of this clinical issue cannot be underestimated, given its high frequency, the possible adverse effects of depression on disease course [18], cognitive functioning [19], treatment adherence [20], deleterious consequences on quality of life [21], and increased risk of suicide [22, 23].

Unfortunately, mental comorbidity and depression in particular are frequently underdiagnosed and undertreated, with reported rates of missed diagnosis around $23-30 \%$ $[6,24]$ and rates of inadequate treatment around $20 \%-36 \%$ of those reporting depression $[6,25]$. In a cross-sectional community study of patients with MS by Cetin et al. [26], 59\% of the patients who had significant symptoms of depression were not taking medication, possibly due to missed diagnosis, denial of symptoms, or false reporting, whereas the rest $41 \%$ received inadequate treatment. In the whole sample $(n=542), 28 \%$ of the patients were adequately treated for depression and therefore had achieved remission. In another study by Mohr et al. [27], $65.6 \%$ of depressed patients did not receive medication, $4,7 \%$ received subthreshold treatment, $26,6 \%$ received threshold, and only 
$3.1 \%$ received overthreshold, indicating that in most cases, therapy is not in accordance with treatment guidelines for depression. Given the fact that depression is a treatable condition, correct diagnosis and adequate treatment are issues of immense importance for the management of multiple sclerosis patients.

The present paper is focused on current knowledge on diagnosis, assessment, and therapeutic interventions for depression in the context of multiple sclerosis.

\section{Diagnosis and Assessment}

2.1. General Considerations. Although the symptom of depressive mood is almost always experienced by patients suffering from disabling diseases, the syndrome of major depression, as defined by the classification systems of ICD-10 [28] and DSM-IV-TR [29], corresponds to a constellation of symptoms comprising depressive mood, anhedonia, fatigue, psychomotor retardation or restlessness, suicidal ideation or suicide attempt, feelings of guilt and worthlessness, and difficulty in concentrating, as well as vegetative symptoms, including altered sleep, appetite, and sexual arousal [30]. A common challenge for correctly diagnosing depression in the context of multiple sclerosis is distinguishing whether a certain symptom emanates from a depressive disorder or can be attributed to the demyelinating disease. Potential confounders are fatigue, insomnia, altered appetite, and impaired memory and concentration, and misjudgments will lead to false positives or false negatives. Varied presentations of depression, for example, unexplained somatic complaints, anxiety, or hopelessness instead of sadness, could also complicate diagnosis, especially in older persons [31]. Patients with MS might exhibit pathological laughter or crying occurring with bilateral forebrain disease, which poorly correlates with underlying mood [1]. On the other hand, depression adversely affects appraisal of physical symptoms $[32,33]$. A way of disentangling the differential diagnosis in such cases is by paying attention to the cognitive and affective domains of the depressive symptomatology, for example, the depressive mood and depressive beliefs, which is also an approach adopted by assessment tools and rating scales for depression in the presence of a physical illness and multiple sclerosis in particular [12].

2.2. Screening and Assessment Tools. The use of two screening questions [34] has been proposed for detecting major depressive disorder in the context of MS and primary care setting [35], which correspond to depressive mood ("during the last two weeks, have you often been bothered by feeling down, depressed, or hopeless?") and anhedonia ("during the past two weeks, have you often been bothered by little interest or pleasure in doing things?"). At least one affirmative response on either question was used as a criterion of having MDD. This approach was shown to have a positive predictive value of $71.7 \%$, with a rate of $27.3 \%$ of false positives. However, two thirds of false positives were shown to have subthreshold depression, which again should alert the clinician for the need of treatment [35]. Using the Yale single question [36] is even less time consuming, but this tool seems to lack sensitivity, as it could not identify $34.7 \%$ of patients who were depressed by Beck Depression Inventory criteria. On the other hand, it appears to be quite specific, that is, depression can be ruled out when it does not exist [37].

The Beck Depression Inventory [38] is an objective selfreport assessment tool comprising 21 items, and one of the most commonly used for patients with multiple sclerosis. Recommended cutoff point is set at 13, though 30\% of patients with depression will be missed in this way [8]. Concerns regarding the length of the instrument as well as the inclusion of items corresponding to neurovegetative symptoms, which might lead to overdiagnosis, have led to the implementation of shorter forms, such as the 7-item Beck Depression Inventory-Fast Screen (BDI-FS) [39]. Validity of the instrument has been documented for the population of patients with multiple sclerosis [40].

The Hospital Anxiety and Depression Scale [41] is a selfassessed questionnaire consisting of 14 items, suitable for use in persons with medical conditions, if items corresponding to somatic symptoms are omitted [42], and recently validated for people with multiple sclerosis [43].

The Center for Epidemiologic Studies Depression Rating Scale (CES-D) [44], comprising 20 items, has been used with a cutoff point of $16(>15)$, as likely to correspond to significant depression, recognizing $74.5 \%$ of depressed persons $[9,45]$. Another useful scale is the Chicago Multiscale Depression Inventory that was developed to assess depression in MS and other chronic diseases [46]. It is a 42 -item selfreporting questionnaire consisting of three subscales, mood, physical malfunctioning, and self-criticism, the first of which is recommended for MS [47]. The validity of the use of the Hamilton Rating Scale for Depression [48] has been examined in one study [49]. The authors conclude that the whole or part of the scale can be used, depending on study design. The Depressive Mood Scale (EHD, Echelle d' Humeur Dépressive) is an 11-item French questionnaire specifically designed and validated for the assessment of depression in MS, focusing on mood changes rather than somatic symptoms [50]. The Zung Self-Rating Depression Scale (ZSRD) [51] is a 20-item tool that has been shown to have good construct validity for measuring depression in medically ill populations [52] and has been used for patients with MS [53, 54], as well as the Montgomery-Asberg Rating Scale (MADRS) [55], a widely known clinician-rated assessment tool for depression, consisting of 10 items [56].

In pediatric populations, researchers most frequently use the Child Depression Inventory for identifying depression in samples with MS $[57,58]$. The presence of depression can also be documented by applying the Kiddie-SADS interview [59].

The utility of detecting depression partly depends on the efficacy and availability of treatments as well as willingness of patients to receive treatment. In a recent study, less than $30 \%$ of depressive individuals who were prompted to receive treatment did so, and possible explanations for this were distorted beliefs of depression being inevitable, practical problems, or the depression itself $[60,61]$. Concluding, identifying depression, though not sufficient to ensure 
effective treatment, is a necessary first step towards proper management of depressed patients with multiple sclerosis.

\section{Treatment Approaches}

3.1. General Considerations. A comprehensive treatment plan for depression should include pharmacotherapy, psychotherapy, or cognitive behavioural therapy in specific or combination therapy. Screening for suicidal intend is incremental due to the high cumulative lifetime risk for suicide [7].

Treating depression has been found to improve adherence [20], cognitive disturbances [62], fatigue [63], quality of life [64], and possibly disease course, by decreasing production of cytokine [18]. There is a growing body of evidence regarding the neuroprotective effects of antidepressants such as fluoxetine [65] and phenelzine [66]. Furthermore, escitalopram has been found to reduce stress-related relapses in a recent open-label, randomized, controlled study [67].

Treatment guidelines have been most recently reported by the Canadian Network for Mood and Anxiety Disorders (CANMAT), based on up-to-date literature [68]. Use of antidepressants is strongly recommended, as well as psychotherapies emphasizing coping strategies rather than insight. SSRIs are considered well-tolerated first-line treatment. Drugs with significant sedating or anticholinergic side effects, such as tricyclic antidepressants, should rather be avoided, due to issues with fatigue, orthostatic hypotension, balance, cognitive disturbances, and bladder problems. Patients should also be monitored for manic or hypomanic symptoms, while on antidepressant medication, as the prevalence of bipolar disorder is quite elevated in MS, presumably two to three times higher than in the general population [6]. Should depression emerge during treatment with interferon beta, the latter needs not necessarily be discontinued, but the depression should be adequately treated instead [12].

3.2. Somatic Treatment. Despite the high burden of depression in multiple sclerosis patients, few trials have been published regarding this particular population, and only two of them were double blind, randomized, placebo controlled, and meeting certain standards of quality, as already observed by Koch et al. [69]. The first one examined the efficacy of desipramine versus placebo and found a trend in favor of desipramine [70]. The second demonstrated greater efficacy of paroxetine versus placebo, with $78.6 \%$ versus $42.1 \%$ of patients exhibiting response, respectively, but the difference did not reach significance, probably because of underpowering of the study and dosing and duration issues [71]. Another problem faced by both studies was missing data or patients who were lost at followup [69].

In another study by Mohr et al. [72], sertraline was found to be equally effective with cognitive behavioural therapy, and both of them were more efficacious than supportive-expressive therapy in a sample of 63 depressed patients with multiple sclerosis. Open-label studies have demonstrated efficacy of sertraline [73], fluvoxamine [74], moclobemide [75], and fluoxetine [76]. Common side effects were gastrointestinal such as nausea, vomiting, and headache. Unfortunately, evidence documenting therapeutic interventions for the pediatric population is lacking [77].

A few case reports deal with the usefulness of ECT for severe or refractory depression in MS [78]; however, concerns have been raised that ECT might mediate neurological deterioration by altering the number or size of the CNS plaques and/or periplaque edema $[79,80]$. It has been postulated that the presence of contrast-enhanced lesions might predict deterioration, and therefore, a gadoliniumenhanced MRI is suggested, but this observation is based on a report of only three patients, one of whom deteriorated after ECT sessions [81].

3.3. Psychotherapeutic Interventions. Psychotherapy has long been considered an important treatment option for the management of depression in patients with MS, with approaches focusing on coping skills showing superiority over insightoriented therapies [82]. Cognitive behaviour therapy (CBT) helps patients to correct distorted cognitive appraisal of the environment and core beliefs that lead to maladaptive behaviour, and change the connection between life events and learned reactions such as depression beliefs [83]. Regarding multiple sclerosis in particular, which imposes progressively increasing physical difficulties and challenges in everyday living, together with cognitive impairment, CBT can help maximize the development of the patients' coping skills [82]. In line with this observation, individual (CBT) has been found more beneficial than supportive expressive therapy (SET), administered either as usual [72] or by telephone [84]. Telephone-administered psychotherapy or counseling is particularly appealing because of the frequent physical disability, which represents an obstacle to receiving therapy otherwise [85]. For similar reasons, computerized forms of CBT are also available $[86,87]$. Group CBT has yielded beneficial results, as well [80]. On the other hand, there still may be some patients who would benefit more by insight-oriented, psychodynamic psychotherapy, which focuses on the management of psychological defenses and unconscious psychic activity $[82,88]$. The effectiveness of mindful-based intervention (MBI) which is based on the nonjudgmental awareness of everyday moments has also been recently demonstrated [89]. Both CBT and MBI cannot be used by persons with significant cognitive impairment. Finally, other studies have demonstrated the beneficial effects of interpersonal therapy [90]. Individual preference and needs, cognitive performance, and availability of therapist should help the clinician choose among the above diverse psychotherapeutic approaches.

\section{Concluding Remarks}

The prevalence of depression in patients is remarkably high, yet it is still frequently underdiagnosed and undertreated. Patients who are not treated are not expected to improve and are at risk for further deterioration. Clinicians should be alert for the risk of suicide and the need for treatment. More and better designed studies for therapeutic interventions, particularly in the pediatric populations, are clearly needed. 


\section{Conflict of Interests}

The authors declared that there is no conflict of interests.

\section{References}

[1] T. Paparrigopoulos, P. Ferentinos, A. Kouzoupis, G. Koutsis, and G. N. Papadimitriou, "The neuropsychiatry of multiple sclerosis: focus on disorders of mood, affect and behaviour," International Review of Psychiatry, vol. 22, no. 1, pp. 14-21, 2010.

[2] E. Koutsouraki, V. Costa, and S. Baloyannis, "Epidemiology of multiple sclerosis in Europe: a review," International Review of Psychiatry, vol. 22, no. 1, pp. 2-13, 2010.

[3] O. Kantarci and D. Wingerchuk, "Epidemiology and natural history of multiple sclerosis: new insights," Current Opinion in Neurology, vol. 19, no. 3, pp. 248-254, 2006.

[4] T. Chitnis, B. Glanz, S. Jaffin, and B. Healy, "Demographics of pediatric-onset multiple sclerosis in an MS center population from the Northeastern United States," Multiple Sclerosis, vol. 15 , no. 5, pp. 627-631, 2009.

[5] M. A. Butler and T. L. Bennett, "In search of a conceptualization of multiple sclerosis: a historical perspective," Neuropsychology Review, vol. 13, no. 2, pp. 93-112, 2003.

[6] R. A. Marrie, R. Horwitz, G. Cutter, T. Tyry, D. Campagnolo, and T. Vollmer, "The burden of mental comorbidity in multiple sclerosis: frequent, underdiagnosed, and undertreated," Multiple Sclerosis, vol. 15, no. 3, pp. 385-392, 2009.

[7] M. A. Raskind, "Diagnosis and treatment of depression comorbid with neurologic disorders," American Journal of Medicine, vol. 121, no. 11, pp. S28-S37, 2008.

[8] Goldman Consensus Group, "The Goldman Consensus statement on depression in multiple sclerosis," Multiple Sclerosis, vol. 11, no. 3, pp. 328-337, 2005.

[9] S. B. Patten, S. Berzins, and L. M. Metz, "Challenges in screening for depression in multiple sclerosis," Multiple Sclerosis, vol. 16, no. 11, pp. 1406-1411, 2010.

[10] L. Chwastiak, D. M. Ehde, L. E. Gibbons, M. Sullivan, J. D. Bowen, and G. H. Kraft, "Depressive symptoms and severity of illness in multiple sclerosis: epidemiologic study of a large community sample," American Journal of Psychiatry, vol. 159, no. 11, pp. 1862-1868, 2002.

[11] D. M. Weisbrot, A. B. Ettinger, K. D. Gadow et al., "Psychiatric comorbidity in pediatric patients with demyelinating disorders," Journal of Child Neurology, vol. 25, no. 2, pp. 192-202, 2010.

[12] A. Feinstein, "Multiple sclerosis and depression," Multiple Sclerosis Journal, vol. 17, no. 11, pp. 1276-1281, 2011.

[13] S. B. Patten, L. M. Metz, and M. A. Reimer, "Biopsychosocial correlates of lifetime major depression in a multiple sclerosis population," Multiple Sclerosis, vol. 6, no. 2, pp. 115-120, 2000.

[14] L. D. Jacobs, R. W. Beck, J. H. Simon et al., "Intramuscular interferon beta-1a therapy initiated during a first demyelinating event in multiple sclerosis," The New England Journal of Medicine, vol. 343, no. 13, pp. 898-904, 2000.

[15] R. J. Siegert and D. A. Abernethy, "Depression in multiple sclerosis: a review," Journal of Neurology, Neurosurgery and Psychiatry, vol. 76, no. 4, pp. 469-475, 2005.

[16] S. B. Patten and L. M. Metz, "Interferon $\beta$ - 1 a and depression in relapsing-remitting multiple sclerosis: An analysis of depression data from the PRISMS clinical trial," Multiple Sclerosis, vol. 7, no. 4, pp. 243-248, 2001.

[17] A. Feinstein, P. O'Connor, and K. Feinstein, "Multiple sclerosis, interferon beta-1b and depression: a prospective investigation," Journal of Neurology, vol. 249, no. 7, pp. 815820, 2002.

[18] D. C. Mohr, D. E. Goodkin, J. Islar, S. L. Hauser, and C. P. Genain, "Treatment of depression is associated with suppression of nonspecific and antigen-specific TH1 responses in multiple sclerosis," Archives of Neurology, vol. 58, no. 7, pp. 1081-1086, 2001.

[19] L. Messinis, M. H. Kosmidis, E. Lyros, and P. Papathanasopoulos, "Assessment and rehabilitation of cognitive impairment in multiple sclerosis," International Review of Psychiatry, vol. 22, no. 1, pp. 22-34, 2010.

[20] D. C. Mohr, D. E. Goodkin, W. Likosky, N. Gatto, K. A. Baumann, and R. A. Rudick, "Treatment of depression improves adherence to interferon beta-1b therapy for multiple sclerosis," Archives of Neurology, vol. 54, no. 5, pp. 531-533, 1997.

[21] O. Kargiotis, A. Paschali, L. Messinis, and P. Papathanasopoulos, "Quality of life in multiple sclerosis: effects of current treatment options," International Review of Psychiatry, vol. 22, no. 1, pp. 67-82, 2010.

[22] A. P. Turner, R. M. Williams, J. D. Bowen, D. R. Kivlahan, and J. K. Haselkorn, "Suicidal ideation in multiple sclerosis," Archives of Physical Medicine and Rehabilitation, vol. 87, no. 8, pp. 1073-1078, 2006.

[23] E. D. Caine and S. R. Schwid, "Multiple sclerosis, depression, and the risk of suicide," Neurology, vol. 59, no. 5, pp. 662-663, 2002.

[24] C. McGuigan and M. Hutchinson, "Unrecognised symptoms of depression in a community-based population with multiple sclerosis," Journal of Neurology, vol. 253, no. 2, pp. 219-223, 2006.

[25] H. L. Tremlett, D. K. Luscombe, and C. M. Wiles, "Prescribing for multiple sclerosis patients in general practice: a case-control study," Journal of Clinical Pharmacy and Therapeutics, vol. 26, no. 6, pp. 437-444, 2001.

[26] K. Cetin, K. L. Johnson, D. M. Ehde, C. M. Kuehn, D. Amtmann, and G. H. Kraft, "Antidepressant use in multiple sclerosis: epidemiologic study of a large community sample," Multiple Sclerosis, vol. 13, no. 8, pp. 1046-1053, 2007.

[27] D. C. Mohr, S. L. Hart, I. Fonareva, and E. S. Tasch, “Treatment of depression for patients with multiple sclerosis in neurology clinics," Multiple Sclerosis, vol. 12, no. 2, pp. 204-208, 2006.

[28] World Health Organization, The ICD-10 Classification of Mental and Behavioural Disorders-Clinical Descriptions and Diagnostic Guidelines, WHO, Geneva, Switzerland, 1993.

[29] American Psychiatric Association, Diagnostic and Statistical Manual of Mental Disorders-DSM-IV-TR, APA, American Psychiatric Publishing, Arlington, Va, USA, 4th ed edition, 2000.

[30] H. S. Akiskal, "Mood disorders: clinical features," in Comprehensive Textbook of Psychiatry, V. A. Sadock, \#x26, and V. A. Sadock, Eds., Lippincott Williams \& Wilkins, Philadelphia, Pa, USA, 2009.

[31] J. J. Gallo and P. V. Rabins, "Depression without sadness: alternative presentations of depression in late life," American Family Physician, vol. 60, no. 3, pp. 820-826, 1999.

[32] E. A. Leventhal, S. Hansell, M. Diefenbach, H. Leventhal, and D. C. Glass, "Negative affect and self-report of physical symptoms: two longitudinal studies of older adults," Health Psychology, vol. 15, no. 3, pp. 193-199, 1996.

[33] C. McGuigan, A. McCarthy, and M. Hutchinson, "Influence of depression on self reporting of the physical impact of multiple sclerosis in two community based populations," Journal of 
Neurology Neurosurgery and Psychiatry, vol. 74, no. 3, pp. 408408, 2003.

[34] M. A. Whooley, A. L. Avins, J. Miranda, and W. S. Browner, "Case-finding instruments for depression: two questions are as good as many," Journal of General Internal Medicine, vol. 12, no. 7, pp. 439-445, 1997.

[35] D. C. Mohr, S. L. Hart, L. Julian, and E. S. Tasch, "Screening for depression among patients with multiple sclerosis: two questions may be enough," Multiple Sclerosis, vol. 13, no. 2, pp. 215-219, 2007.

[36] M. S. Lachs, A. R. Feinstein, L. M. Cooney et al., "A simple procedure for general screening for functional disability in elderly patients," Annals of Internal Medicine, vol. 112, no. 9, pp. 699706, 1990.

[37] J. R. Avasarala, A. H. Cross, and K. Trinkaus, "Comparative assessment of yale single question and Beck depression inventory Scale in screening for depression in multiple sclerosis," Multiple Sclerosis, vol. 9, no. 3, pp. 307-310, 2003.

[38] A. T. Beck, C. H. Ward, M. Mendelson, J. Mock, and J. Erbaugh, "An inventory for measuring depression," Archives of General Psychiatry, vol. 4, no. 6, pp. 561-571, 1961.

[39] A. T. Beck and G. K. Brown, Eds., BDI-Fast Screen for Medical Patients: Manual, Psychological Corporation, San Antonio, Tex, USA, 2000.

[40] R. H. B. Benedict, I. Fishman, M. M. McClellan, R. Bakshi, and B. Weinstock-Guttman, "Validity of Beck Depression Inventory-Fast Screen in multiple sclerosis," Multiple Sclerosis, vol. 9, no. 4, pp. 393-396, 2003.

[41] A. S. Zigmond and R. P. Snaith, "The hospital anxiety and depression scale," Acta Psychiatrica Scandinavica, vol. 67, no. 6, pp. 361-370, 1983.

[42] C. Herrmann, "International experiences with the hospital anxiety and depression scale - a review of validation data and clinical results," Journal of Psychosomatic Research, vol. 42, no. 1, pp. 17-41, 1997.

[43] K. Honarmand and A. Feinstein, "Validation of the Hospital Anxiety and Depression Scale for use with multiple sclerosis patients," Multiple Sclerosis, vol. 15, no. 12, pp. 1518-1524, 2009.

[44] I. McDowell, Ed., Measuring Health, a Guide to Rating Scales and Questionnaires, Oxford University Press, New York, NY, USA, 1996.

[45] S. B. Patten, S. Fridhandler, C. A. Beck, and L. M. Metz, "Depressive symptoms in a treated multiple sclerosis cohort," Multiple Sclerosis, vol. 9, no. 6, pp. 616-620, 2003.

[46] D. L. Nyenhuis, T. Luchetta, C. Yamamoto et al., "The development, standardization, and initial validation of the Chicago Multiscale Depression Inventory," Journal of Personality Assessment, vol. 70, no. 2, pp. 386-401, 1998.

[47] A. Solari, A. Motta, L. Mendozzi et al., "Italian version of the Chicago multiscale depression inventory: translation, adaptation and testing in people with multiple sclerosis," Neurological Sciences, vol. 24, no. 6, pp. 375-383, 2004.

[48] M. Hamilton, “A rating scale for depression," Journal of Neurology, Neurosurgery, and Psychiatry, vol. 23, pp. 56-62, 1960.

[49] P. J. Moran and D. C. Mohr, "The validity of Beck Depression Inventory and Hamilton Rating Scale for Depression items in the assessment of depression among patients with multiple sclerosis," Journal of Behavioral Medicine, vol. 28, no. 1, pp. 35-41, 2005.

[50] F. Radat, M. Lafittau, J. C. Ouallet, B. Brochet, and R. Jouvent, "Validation of EHD self questionnaire in multiple sclerosis," Encephale, vol. 33, no. 1, pp. 49-57, 2007.
[51] W. W. ZUNG, "A self-rating depression scale," Archives of General Psychiatry, vol. 12, pp. 63-70, 1965.

[52] K. K. Leung, B. H. Lue, M. B. Lee, and L. Y. Tang, "Screening of depression in patients with chronic medical diseases in a primary care setting," Family Practice, vol. 15, no. 1, pp. 6775, 1998.

[53] D. C. Kroencke, S. G. Lynch, and D. R. Denney, "Fatigue in multiple sclerosis: relationship to depression, disability, and disease pattern," Multiple Sclerosis, vol. 6, no. 2, pp. 131-136, 2000.

[54] S. Fruewald, H. Loeffler-Stastka, R. Eher, B. Saletu, and U. Baumhacki, "Depression and quality of life in multiple sclerosis," Acta Neurologica Scandinavica, vol. 104, no. 5, pp. 257261, 2001.

[55] S. A. Montgomery and M. Asberg, "A new depression scale designed to be sensitive to change," British Journal of Psychiatry, vol. 134, no. 4, pp. 382-389, 1979.

[56] S. R. Montel and C. Bungener, "Coping and quality of life in one hundred and thirty five subjects with multiple sclerosis," Multiple Sclerosis, vol. 13, no. 3, pp. 393-401, 2007.

[57] I. A. Ketelslegers, C. E. Catsman-Berrevoets, M. Boon et al., "Fatigue and depression in children with multiple sclerosis and monophasic variants," European Journal of Paediatric Neurology, vol. 14, no. 4, pp. 320-325, 2010.

[58] B. Goretti, E. Portaccio, A. Ghezzi et al., "Fatigue and its relationships with cognitive functioning and depression in paediatric multiple sclerosis," Multiple Sclerosis Journal, vol. 18, no. 3, pp. 329-334, 2012.

[59] J. Kaufman, B. Birmaher, D. Brent et al., "Schedule for affective disorders and schizophrenia for school-age children-present and lifetime version (K-SADS-PL): initial reliability and validity data," Journal of the American Academy of Child and Adolescent Psychiatry, vol. 36, no. 7, pp. 980-988, 1997.

[60] A. C. Sollom and I. I. Kneebone, "Treatment of depression in people who have multiple sclerosis," Multiple Sclerosis, vol. 13, no. 5, pp. 632-635, 2007.

[61] K. Bristow and S. Patten, "Treatment-seeking rates and associated mediating factors among individuals with depression," Canadian Journal of Psychiatry, vol. 47, no. 7, pp. 660-665, 2002.

[62] J. A. Wilken and C. Sullivan, "Recognizing and treating common psychiatric disorders in multiple sclerosis," Neurologist, vol. 13, no. 6, pp. 343-354, 2007.

[63] D. C. Mohr, S. L. Hart, and A. Goldberg, "Effects of treatment for depression on fatigue in multiple sclerosis," Psychosomatic Medicine, vol. 65, no. 4, pp. 542-547, 2003.

[64] S. Hart, I. Fonareva, N. Merluzzi, and D. C. Mohr, "Treatment for depression and its relationship to improvement in quality of life and psychological well-being in multiple sclerosis patients," Quality of Life Research, vol. 14, no. 3, pp. 695-703, 2005.

[65] P. E. Sijens, J. P. Mostert, R. Irwan, J. H. Potze, M. Oudkerk, and J. De Keyser, "Impact of fluoxetine on the human brain in multiple sclerosis as quantified by proton magnetic resonance spectroscopy and diffusion tensor imaging," Psychiatry Research, vol. 164, no. 3, pp. 274-282, 2008.

[66] T. Musgrave, C. Benson, G. Wong et al., "The MAO inhibitor phenelzine improves functional outcomes in mice with experimental autoimmune encephalomyelitis (EAE)," Brain, Behavior, and Immunity, vol. 25, no. 8, pp. 1677-1688, 2011.

[67] C. I. Mitsonis, I. M. Zervas, C. M. Potagas et al., "Effects of escitalopram on stress-related relapses in women with multiple sclerosis: an open-label, randomized, controlled, one-year 
follow-up study," European Neuropsychopharmacology, vol. 20, no. 2, pp. 123-131, 2010.

[68] R. Ramasubbu, V. H. Taylor, Z. Saaman et al., "The Canadian Network for Mood and Anxiety Treatments (CANMAT) task force recommendations for the management of patients with mood disorders and select comorbid medical conditions," Annals of Clinical Psychiatry, vol. 24, no. 1, pp. 91-109, 2012.

[69] M. W. Koch, A. Glazenborg, M. Uyttenboogaart, J. Mostert, and J. De Keyser, "Pharmacologic treatment of depression in multiple sclerosis," Cochrane Database of Systematic Reviews, vol. 2, Article ID CD007295, 2011.

[70] R. B. Schiffer and N. M. Wineman, "Antidepressant pharmacotherapy of depression associated with multiple sclerosis," American Journal of Psychiatry, vol. 147, no. 11, pp. 1493-1497, 1990.

[71] D. M. Ehde, G. H. Kraft, L. Chwastiak et al., "Efficacy of paroxetine in treating major depressive disorder in persons with multiple sclerosis," General Hospital Psychiatry, vol. 30, no. 1, pp. 40-48, 2008.

[72] D. C. Mohr, A. C. Boudewyn, D. E. Goodkin, A. Bostrom, and L. Epstein, "Comparative outcomes for individual cognitivebehavior therapy, supportive-expressive group psychotherapy, and sertraline for the treatment of depression in multiple sclerosis," Journal of Consulting and Clinical Psychology, vol. 69, no. 6, pp. 942-949, 2001.

[73] T. F. Scott, P. Nussbaum, H. McConnell, and P. Brill, "Measurement of treatment response to sertraline in depressed multiple sclerosis patients using the Carroll scale," Neurological Research, vol. 17, no. 6, pp. 421-422, 1995.

[74] F. Benedetti, E. Campori, C. Colombo, and E. Smeraldi, "Fluvoxamine treatment of major depression associated with multiple sclerosis," Journal of Neuropsychiatry and Clinical Neurosciences, vol. 16, no. 3, pp. 364-366, 2004.

[75] Y. Barak, E. Ur, and A. Achiron, "Moclobemide treatment in multiple sclerosis patients with comorbid depression: an open-label safety trial," Journal of Neuropsychiatry and Clinical Neurosciences, vol. 11, no. 2, pp. 271-273, 1999.

[76] Y. Barak, A. Achiron, D. Shoshani, and A. Elizur, "Fluoxetine treatment of depression in patients suffering from multiple sclerosis," Human Psychopharmacology-Clinical and Experimental, vol. 13, no. 1, pp. 66-67, 1998.

[77] E. A. Yeh, "Current therapeutic options in pediatric multiple sclerosis," Current Treatment Options in Neurology, vol. 13, no. 6, pp. 544-559, 2011.

[78] K. G. Rasmussen and B. M. Keegan, "Electroconvulsive therapy in patients with multiple sclerosis," Journal of ECT, vol. 23, no. 3, pp. 179-180, 2007.

[79] E. Corruble, H. Awad, G. Chouinard, and P. Hardy, "ECT in delusional depression with multiple sclerosis," American Journal of Psychiatry, vol. 161, no. 9, p. 1715, 2004.

[80] M. T. Wallin, J. A. Wilken, A. P. Turner, R. M. Williams, and R. Kane, "Depression and multiple sclerosis: review of a lethal combination," Journal of Rehabilitation Research and Development, vol. 43, no. 1, pp. 45-62, 2006.

[81] G. Mattingly, K. Baker, C. F. Zorumski, and G. S. Figiel, "Multiple sclerosis and ECT: possible value of gadoliniumenhanced magnetic resonance scans for identifying highrisk patients," Journal of Neuropsychiatry and Clinical Neurosciences, vol. 4, no. 2, pp. 145-151, 1992.

[82] D. C. Mohr and D. E. Goodkin, "Treatment of depression in multiple sclerosis: review and meta-analysis," Clinical Psychology: Science and Practice, vol. 6, no. 1, pp. 1-9, 1999.

[83] R. Litta, "Non-pharmacological treatment of depression," Neurological Sciences, vol. 27, no. 4, pp. S344-S346, 2006.
[84] D. C. Mohr, S. L. Hart, L. Julian et al., "Telephone-administered psychotherapy for depression," Archives of General Psychiatry, vol. 62, no. 9, pp. 1007-1014, 2005.

[85] D. S. Dorstyn, J. L. Mathias, and L. A. Denson, "Psychosocial outcomes of telephone-based counseling for adults with an acquired physical disability: a meta-analysis," Rehabilitation Psychology, vol. 56, no. 1, pp. 1-14, 2011.

[86] C. L. Cooper, D. Hind, G. D. Parry et al., "Computerised cognitive behavioural therapy for the treatment of depression in people with multiple sclerosis: external pilot trial," Trials, vol. 12, article 259, 2011.

[87] R. Moss-Morris, P. McCrone, L. Yardley, K. van Kessel, G. Wills, and L. Dennison, "A pilot randomised controlled trial of an Internet-based cognitive behavioural therapy selfmanagement programme (MS Invigor8) for multiple sclerosis fatigue," Behaviour Research and Therapy, vol. 50, no. 6, pp. 415-421, 2012.

[88] A. Stathopoulou, P. Christopoulos, E. Soubasi, and P. Gourzis, "Personality characteristics and disorders in multiple sclerosis patients: assessment and treatment," International Review of Psychiatry, vol. 22, no. 1, pp. 43-54, 2010.

[89] P. Grossman, L. Kappos, H. Gensicke et al., "MS quality of life, depression, and fatigue improve after mindfulness training: a randomized trial," Neurology, vol. 75, no. 13, pp. 1141-1149, 2010.

[90] A. van Straten, A. Geraedts, I. Verdonck-de Leeuw, G. Andersson, and P. Cuijpers, "Psychological treatment of depressive symptoms in patients with medical disorders: a meta-analysis," Journal of Psychosomatic Research, vol. 69, no. 1, pp. 2332, 2010. 


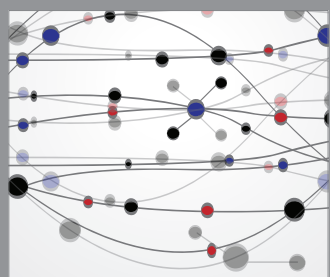

The Scientific World Journal
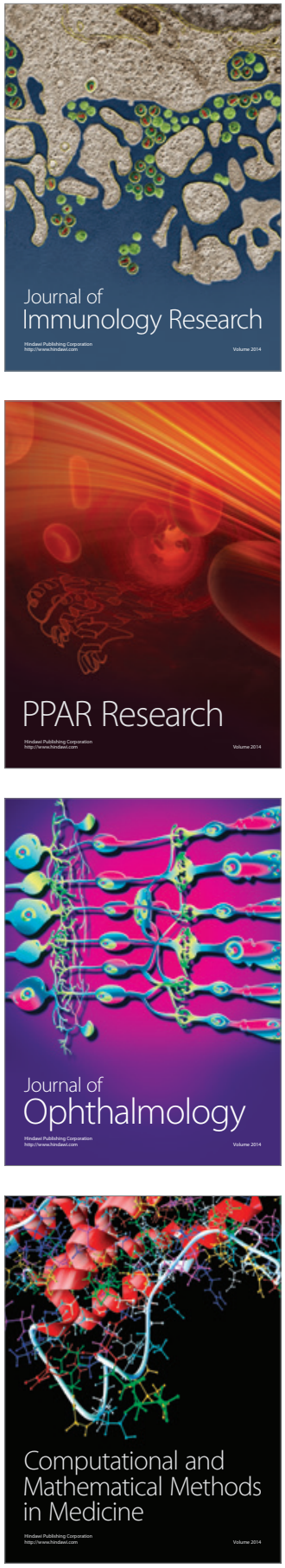

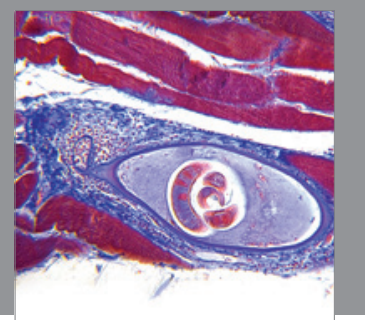

Gastroenterology

Research and Practice
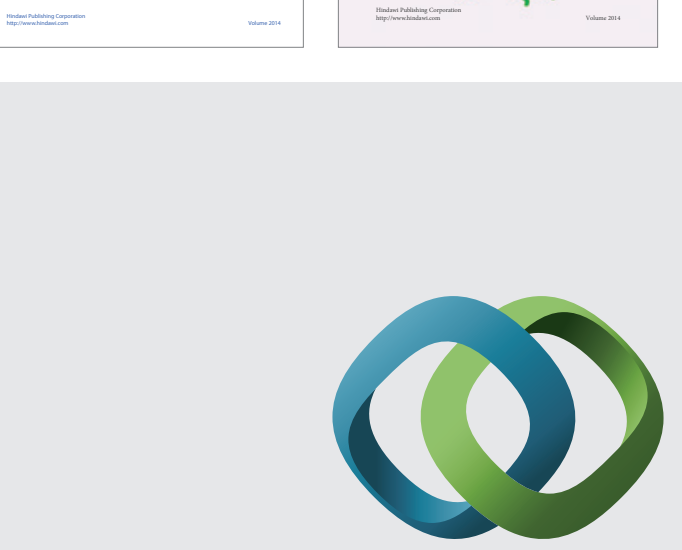

\section{Hindawi}

Submit your manuscripts at

http://www.hindawi.com
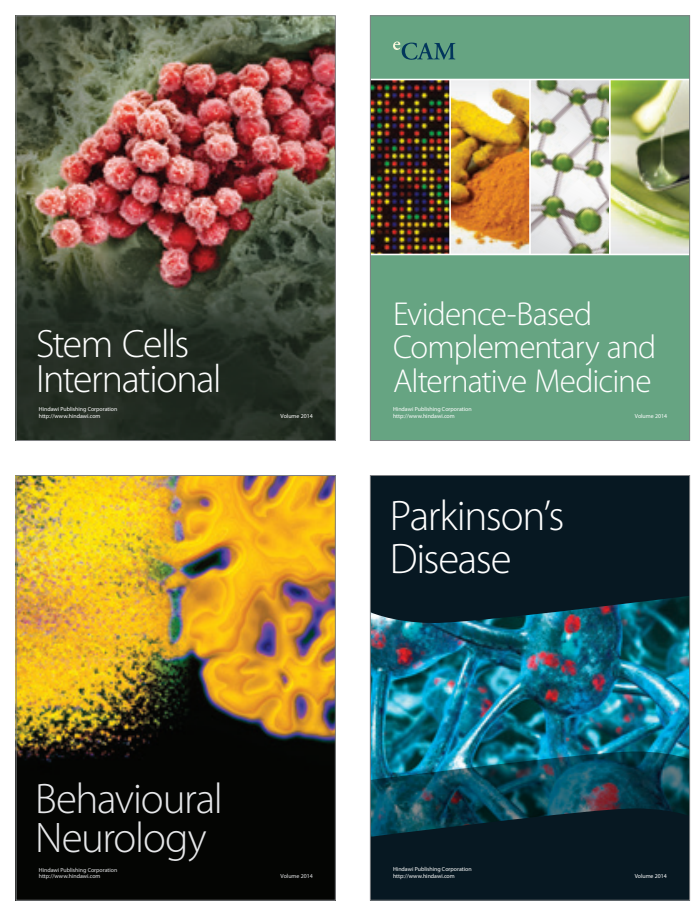

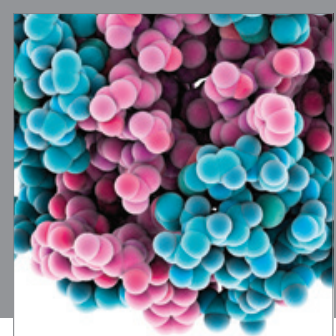

Journal of
Diabetes Research

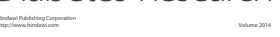

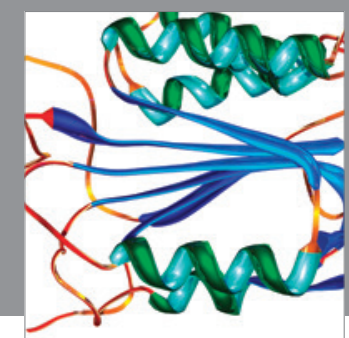

Disease Markers
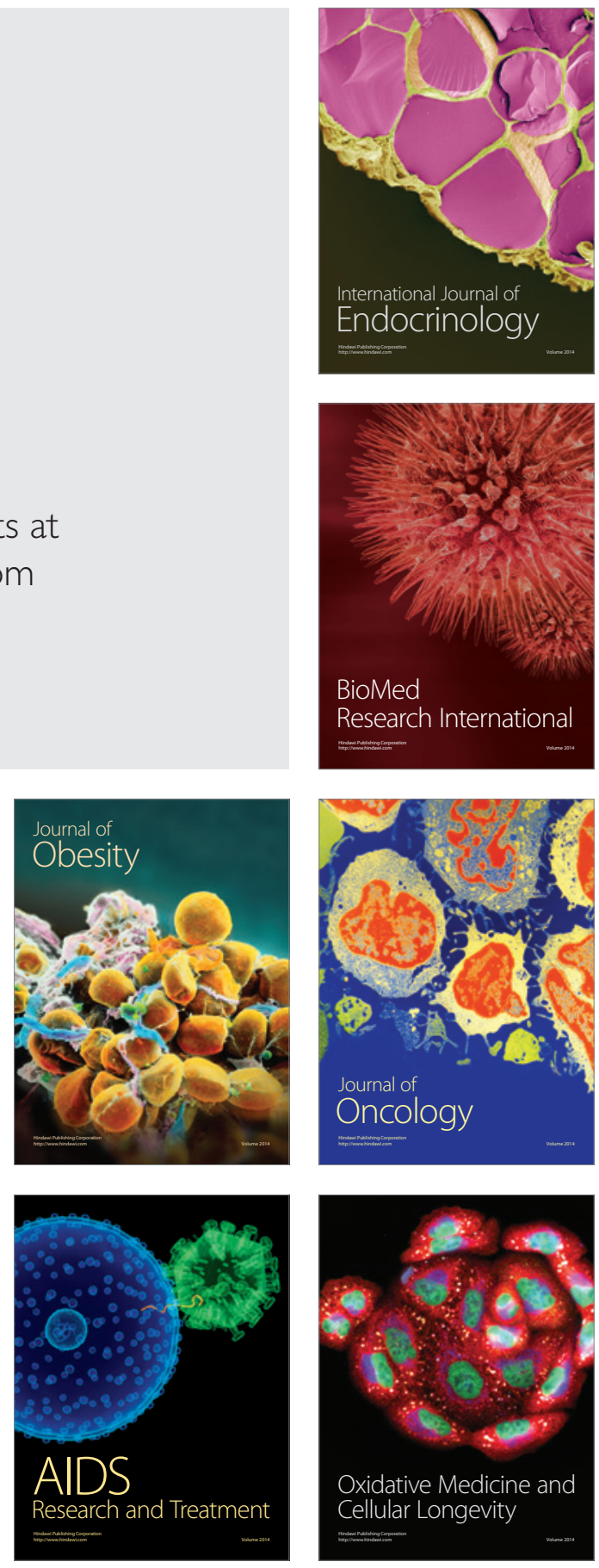